\title{
INTEGRATION PROBLEMS OF PHOTOVOLTAIC SYSTEMS-WIND POWER, SOLUTIONS AND EFFECTS ON POWER QUALITY
}

\author{
Mehmet Rida TUR ${ }^{I^{*}}$, Mohammad WADI ${ }^{2}$, Abdulfetah SHOBOLE ${ }^{3}$, Hasan GUNDUZ ${ }^{4}$
}

\begin{abstract}
Renewable Energy Sources (RES) are growing steadily in power systems, which is expected to meet most of the electricity demand in the future. Today, solar and wind energy sources are spreading at a great speed, which creates difficulties in handling the discrete nature of solar energy. In this study, the effects of grid integration problem and wind energy (WP) applications of photovoltaic $(P V)$ systems were investigated. The best design of sizing and positioning planning in RES based distributed systems are also examined. In addition, it has been determined that the integration of renewable energybased distributed production into power systems is very difficult and critical. Providing a sustainable energy source in power systems is just one of these challenges. Accordingly, the integration of WP and PV based production into the grid in proportion to the energy source may negatively affect the power system by reducing its reliability. It also sets some rules for connecting generators to the grid to ensure that the system continues to operate well and safely in terms of resource security, reliability and power quality (PQ). Thus, these rules, called network codes, regulate the conditions for transmission and distribution system users. This fundamental issues related article also $P Q$, the basic rules are desirable for wind turbines in different countries of the grid codes, compliance with the rules of the wind turbines and rules to be complied with wind power plants in Turkey were examined.
\end{abstract}

Key words: Photovoltaic systems, Wind Power, Integration problems, Power quality, Renewable energy sources, Grid Code.

\section{Introduction}

The share of Renewable Energy Sources (RER) in the installed capacity is increasing day by day. Environmental impacts and energy independence are available as an alternative to fossil fuel production, which is the main driver of increased distribution. In recent years, the aim of study is almost all electricity demand seems to be more favorable as simply procuring from renewable sources. The National Renewable Energy Laboratory (NREL) estimates that by 2050, 80 percent of US electricity production will be supplied from renewable sources. Installed power in renewable energy in the world last year increased by 7.9 percent compared to the previous year rose to 2 thousand 351 gigawatts.

\footnotetext{
${ }^{1}$ Department of Electrical Energy, University of Batman, Batman, Turkey, (mrida.tur@batman.edu.tr) (Dhttps://orcid.org/0000$0001-5688-4624$

2 Department of Electrical\&Electronics Engineering, University of İstanbul Sabahattin Zaim, İstanbul, Turkey, (mohammed.wadi@izu.edu.tr) Đhttps://orcid.org/0000-0001-8928-3729

3 Department of Electrical\&Electronics Engineering, University of İstanbul Sabahattin Zaim, İstanbul, Turkey, (abdulfetah.shobole@izu.edu.tr) Dhttps://orcid.org/0000-0002-3180-6504

${ }^{4}$ Mus Alpaslan University, Muş, Turkey, (h.gunduz@alparslan.edu.tr) @https://orcid.org/0000-0003-3145-1755 
International Renewable Energy Agency (IRENA) "Renewable Capacity Statistics 2019" report, last year, the share of renewable energy in the world's total capacity reached one-third, he said. According to the report, the installed capacity of renewable energy in the world increased 171 gigawatts in total compared to the previous year. The biggest contribution to this increase came from solar and wind power. Solar energy capacity increased by 94 gigawatts and wind energy by 49 gigawatts. Thus, renewable energy capacity increased by 7.9 percent last year compared to the previous year reached 2 thousand 351 gigawatts. Capacity in hydroelectric energy increased by 21 gigawatts rose to 293 gigawatts thousand. As a result, the share of hydroelectric power in total renewable energy has exceeded 50 percent. The share of solar and wind power capacity in renewable energy has increased to 44 percent. Last year, solar energy capacity was 485 gigawatts and wind energy were 563 gigawatts. Along with all these investments and developments, serious costs are required to expand the increasing demand for power and to provide uninterrupted power to customers [1]. In addition, RER integration has many positive effects, especially power quality, voltage balance, reduction of losses and transmissiondistribution reliability [2].

In the energy sector, developments have led to the development of high WP technologies rather than fixed speed WP. Fixed speed WP is more reliable and simpler, and it has many proven advantages. High WP technologies offer mechanical stress, power loss and limited PQ control, which is undesirable [3]. WP is designed for power control purposes, which controls aerodynamic forces in the rotor, but there are many techniques with power limitation to prevent damage to the mechanism. The most obvious and optimal method of WP control is the stall, i.e. passive control. Another control is the curtain, that is, active control. There are two purposes to verify compliance with GC in wind farms. First of all, it is an important task to show that the codarone corresponds to network coding. In addition, network operators are required to ensure that the new facility does not adversely affect the safe operation of the power system, in order to correctly interpret these requirements, a network code has been defined in the plan. According to ENTSO-E, this identification test is defined as the process of verifying the compliance of production facilities to specifications and conditions according to the network [4].

The PQ that is intended to be provided in the systems can be defined as whether the energy supplied to the user equipment and devices is suitable or suitable [5,6]. Considering that the PQ parameters are changes in the ideal sinusoidal constant frequency (trough, peak, interruption, flicker and harmonics), it can be considered equivalent to voltage quality $[7,8]$. In this study, the effects of voltage quality sub-headings such as flickering, changes in voltage and integration problem during the grid integration of PV systems are investigated. The study is carried out assuming that the PV system is electrically fully on-grid, since PV plants connected to the system always cause serious problems in the electrical system in terms of power quality. The effects of PV systems on PQ have been examined as a general problem in most studies [9].

In order to connect renewable energy systems in parallel with electrical power systems, problems that may arise in measurement, control and protection issues should be investigated. These problems may differ from a small power photovoltaic panel to the connection of large power wind turbines. However, regardless of the power of these local resources connected to the grid, it is a necessity to have systems to separate the connections from the grid in case of failures or power failures in the grid.

The integration of RERs into the energy grid comes to the fore only with problems; environmental benefits in carbon emissions [10,11], energy dependence and safety by reducing dependence on fossil fuels [12], increasing the reliability [13] and flexibility [14] of the energy system, and many economic benefits [15].

In PV power systems, the energy transferred to the grid can be affected directly by external factors (the movement of the clouds) and can vary by $80 \%$ of their nominal capacity. These changes adversely affect the quality of the energy [16]. Many studies have examined the output variations of PV systems [17] and proposed different mitigation methods [18]. Some of the methods that analyze these propositions; Volt-Var control strategies, local control of reactive power, efficient inverters [19], application of storage units [20-24] and the use of forecasting techniques [25,26], mitigating the negative effects of fluctuations in PV systems.

It is important to issue a network code verification plan as well as the code itself [27], which does not need to be separated from the system for interpretation of how each requirement is evaluated [28]. 
However, not every network code is complete with a clear and detailed compliance verification plan [29]. The development of GCs has been extensively studied in the literature [30-33], mostly focusing on technical requirements for large Wind Power Plants-WPP [34-36]. In many studies, due to the continuous revisions made by regulatory frameworks, many reviews have been conducted in recent years, including extensive analysis and comparison of network codes [37, 38].

At the end of 2018, the installed capacity of wind power in the world, which was $2160 \mathrm{MW}$ in the first years when wind power was included in the power market, reached 7,031 MW. The electricity obtained from wind turbines is supplied to the existing electricity grid. In grid-connected WP applications, three aspects are fundamental. The first is the closest secure connection to the mains. This includes determining whether there is sufficient capacity in the network for the connection of the wind farm and the impact that the connection will have on the network and other customers in that region. The second one is related to the operation of the network if the wind farm is included in the system; it is generally about the discrete structure of WP and ensuring that WP does not adversely affect the operation of the network. Third, it is the strategic approach in planning. This is the evaluation of the issues that will enable the maximum number of wind farms to be connected to the system.

Since the effects of the grid integration problem of PV and WP applications are difficult and critical, synchronous integration with other energy sources has the risk of negatively affecting the power system by reducing its reliability. Therefore, it is emphasized to arrange the necessary rules for connecting generators to the network to provide PQ. In addition, the suitability and necessity of PQ related rules were examined.

In the second part of the study, PV systems designed to be connected to the network will be examined, then the energy imbalance amount and the effect parameter for PV will be determined. In the third and fourth sections, Network Connection Conditions and Effects of Wind Turbines are examined. In the next section, the results of the calculations for the System Model have been made and the article has been evaluated and the result has been explained in detail.

\section{Materials and Methods}

A PV system is shown in Figure 1, which shows a schematic diagram of a grid-connected PV system conventionally containing a power grid [39]. The diode prevents reverse current flow in the PV array. In addition, the transformer raises the voltage to the nominal value of the mains voltage and provides electrical isolation between the PV system and the mains. The function of the harmonic filter also eliminates harmonic components other than frequency.

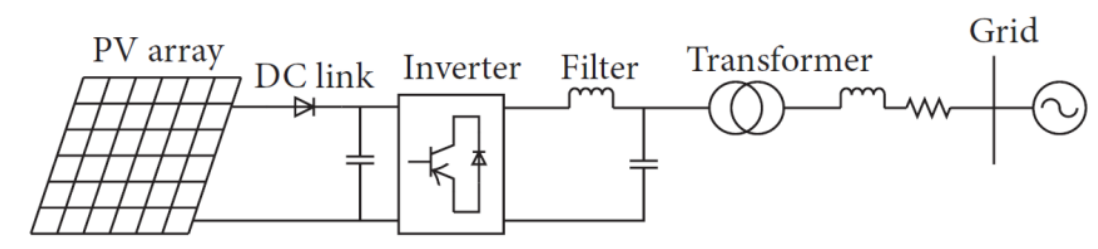

Figure 1. Diagram of a PV system designed to be connected to the grid.

In this study, the effects of PV system on voltage quality were investigated and the changes in the imbalance in the energy market were evaluated. By highlighting the direct impact of developing solar capacity in energy imbalance, the importance of forecasting in the power market has been demonstrated. PV installed capacity of renewable origin Turkey's development over the years the share of total installed power shown as Figure 2. 


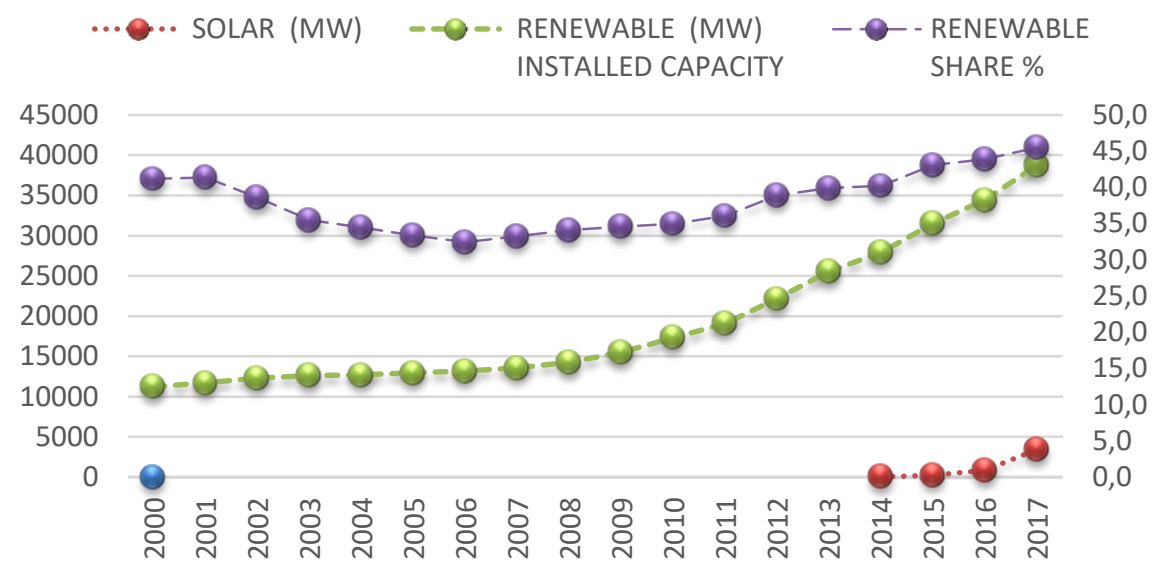

Figure 2. Turkey's development over the years the share of total installed power for solar [40]

\subsection{Determination of energy imbalance quantity and effect parameter for PV}

The amount of energy imbalance, in short, is the difference between the electricity you supply to the electrical system and the electricity you draw from this system. Currently, consensus-truck market in Turkey's electricity amount of energy imbalance (AEI) and period of an hour to an hour is calculated by the following formula 1 .

$$
A E I=(S A-S B)+(A P-G A)+(B D A M-S D A M)+(A L S-A U L)
$$

SA: Settlement amount (You have produced.)

SB: Settlement basis withdrawal amount

AP: The amount of purchase with a bilateral agreement (someone has produced for you and you know that person.)

SV: Sales volume with bilateral agreement

BDAM: Buying from Day Ahead Market (DAM) (Someone has produced it for you and you don't know that person.)

SDAM: Sales amount to Day Ahead Market

ALS: Amount of Load shedding (You are considered to have produced.)

AUL Amount of upload.

You can only write the ones mentioned above in parenthesis in terms of supply to the electrical system in terms of traction from the electrical system. It is worth noting here that: bilateral agreement de in the formula refers to a bilateral agreement between market participants. Market participants; production, auto producer, wholesale, retail sale or companies holding OSB production license. In other words, the electricity that a wholesale company sells to a cement factory is not seen in the bilateral sale of the company, but in the consensus draw.

If we need to explain the imbalance calculation with an example, let us consider an A company that has given $200 \mathrm{MWh}$ electricity urea-type system for 30 May at 12:00 o'clock. Let this company sell 60 MWh of electricity to Day Ahead Market and 100 MWh of electricity to Company X under a bilateral agreement. If company $\mathrm{Y}$ has received a load at $20 \mathrm{MWh}$ at the relevant hour, it has had a positive imbalance of $20 \mathrm{MWh}$ at this hour:

$$
A E I=(200-0)+(0-100)+(0-60)+(0-20)=20 \mathrm{MWh}
$$

Table 1. The meaning of imbalance for producers and consumers

\begin{tabular}{lll}
\hline & Producer & Consumer \\
\hline Positive Imbalance & Over Produce & Consume less \\
Negative Imbalance & Less produce & Over Consume
\end{tabular}


As can be seen from the formula of the amount of energy imbalance, imbalance cannot be destroyed, but can be reduced. State-of-the-art power plants, very good demand forecasts and perfect weather forecasts are not enough to prevent imbalance. An unfulfilled loading instruction, $1^{\circ} \mathrm{C}$ warmer (cooler) air, and wind blowing $1 \mathrm{~m} / \mathrm{s}$ faster (slower) than you might expect, can make you unstable. Electricity is a good whose frequency and voltage must be kept within a certain range. The frequency is kept constant by instantaneous balancing of active energy supply and demand, while the voltage is kept constant by instantaneous balancing of reactive energy supply and demand.

Imbalance can be priced in two ways: single or double. In single pricing, the same price is applied to positive and negative imbalances. This price may be a percentage of the Market Clearing Price (MCP), System Marginal Price (SMP) or another price. In double pricing, separate prices are applied to positive and negative imbalances. These prices can be set in different ways. A percentage of the MCP may be the large or small PTF and SMP, or the large or small MCP and SMP multiplied by a certain coefficient or other prices. The current situation in Turkey is implemented dual pricing in the electricity market and the details are as follows:

- The biggest imbalance of MCP and SMP is applied to negative imbalance. In the case of negative imbalance, the EIA is calculated as follows in eq. 2:

$$
E I A^{-}=E I A^{-} \times \max (M C P, S M P)
$$

- Small imbalance of MCP and SMP is applied to positive imbalance. In the case of positive imbalance, the amount of energy imbalance is calculated as follows in eq. 3 :

$$
E I A^{+}=E I A^{+} \times \min (M C P, S M P)
$$

An unbalanced participant in double pricing is undesirable in the system because of imbalance, at best he remains indifferent; this is the purpose anyway.

\section{Grid Connection Conditions and Effects of Wind Turbines}

Wind turbines PQ defines the electrical performance in the power generation system, which is connected to grid-powered wind turbines, which is effective on power and voltage quality, and is a limiting factor to increase the number of grid-connected wind turbines, especially where the grid is weak.

There are four main factors that affect PQ:

- Voltage step changes

- Flicker

- Harmonic Distortion

- Voltage Unbalance

The characteristics of the wind turbines to be used to estimate the PQ and provide high voltage stability and the condition of the electrical system at the connection point to the mains need to be evaluated correctly. IEC 61400-21 is an international standard that defines calculation methods from appropriate parameters and measurements for determining the PQ of a wind turbine design.

\subsection{Voltage step changes}

Instantaneous voltage change: is the change in voltage that occurs after a switching operation, after the transient regime conditions have been damped, and following the operation of voltage regulators and static VAR compensators, before performing stage settings and other switching 
operations. Sudden drops and surges in the current cause voltage fluctuations, which affect the voltages of other consumers. Such changes can occur much faster than the voltage control systems used in the mains, such as adjusting the tap changer of the main transformer, tolerate these changes, and cause the voltage to fall outside the defined limits at any point in the mains. For safe system operation, electrical network operators set limit values for sudden changes in voltage.

Sudden voltage changes can occur during the commissioning of wind turbines with constant speed induction generators. It is usually a problem in stall regulated wind turbines with constant speed. This is because there is no control when the rotor is accelerating during commissioning. The same effect occurs when moving from one speed to another in two fixed wind turbines. In constant speed machines, "soft transition" power electronics elements are often used to reduce and reduce the sudden voltage changes to negligible levels. In addition, it is accepted that turbines cannot be activated simultaneously in a wind farm.

\subsection{Flicker}

Sudden and minor changes that occur very quickly and repeatedly in the main voltage level are called clipping. Voltage variations caused by undulating loads and / or production are the main cause of complaints on voltage quality. The clipping generated by arc-welding machines, milters and large motors frequently entering and exiting the circuit can be a major problem in weak causes. The most important events in wind turbines; starting and stopping of turbines; and switching between generators in two-speed wind turbines. These transitions can be limited by appropriate turbine control programs. For variable speed wind turbines, clipping is no problem.

Clipping evaluations are performed according to IEC 1000-3-7. The basis of the evaluation is based on a measured curve which gives the visibility threshold for an incandescent filament lamp applied to a square wave. Disturbance visible to the naked eye is referred to as the Pst clipping intensity factor. IEC 1000-3-7 contains values that cannot be exceeded for both clipping levels and the total clipping level.

\subsection{Harmonics}

Harmonic is a phenomenon related to the basic sine wave distortion of the mains voltage. Harmonic distortion is produced by mains-connected non-linear devices such as arc sources, speed controllers, fluorescent lamps, computers, faxes, photocopiers, inverters, etc., and causes different damages depending on the harmonic number and the type of electrical devices. In variable speed wind turbines, power electronic converters that emit frequencies above the base frequency $(50 \mathrm{~Hz}$ or $60 \mathrm{~Hz})$ can cause harmonic currents and customer complaints.

Since the use of power electronic converters in modern wind turbines is becoming more widespread day by day, it is important to determine the harmonics. In wind turbines, pulse width modulation (PWM) converters are generally used to keep harmonic emissions at desired levels. These converters produce very low levels of harmonics (approximately $2 \mathrm{kHz}$ ) and the resulting harmonics are below the level defined by the mains operators. IEC 1000-3-6 outlines planning and compliance for medium and high voltage networks and provides methods for determining the impact each plant has at a level of detailed disturbance.

\subsection{Voltage Imbalance}

Voltage imbalance is often a problem in low voltage networks. In order to keep the voltages constant and the same amplitude in all three phases of the mains, the network operators try to ensure that the currents drawn from all three phases are at the same level. Voltage unbalance is generally evaluated by the power operators within the scope of PQ. An induction generator wind turbine connected to voltage unbalanced networks can act to reduce unbalance.

\section{Grid Codes of Wind Power}

Transmission and distribution network operators set some rules that must be followed by generators to be connected to the network in order to ensure that the power system continues to operate well and safely. The network code documents regulate the requirements for transmission and distribution system users. In order to comply with these rules, WP technology continues to develop by producing new 
solutions especially in the fields of wind turbine and control system design. The aim of the studies is to ensure that wind farms do not adversely affect power system operation in terms of resource security, reliability, and PQ. The basic mains code rules relate to wind turbine behavior in case of frequency, voltage, and mains failures.

\subsection{Frequency Control}

Many reason codes are related to the participation of wind power plants in primary and secondary control as in other plants. Frequency control rules; frequency response capability, bounce rate limitation and active power output. Frequency response - active power output: The frequency response is the ability of the system to change the active power output in response to changes in the system frequency. Bounce rate limitation: Some transmission system operators; may require limitation of the change in the rise or even decrease of the active power output to suppress large frequency fluctuations caused by excessive wind changes and the activation and deactivation of wind power plants. When the wind power in the grid reaches high rates, these rules are expected to become more stringent so that conventional power plants responsible for primary and secondary control do not exceed the power changeover.

\subsection{Voltage control}

The basic rule of network codes is; Wind turbines are required to operate at nominal output power in the nominal voltage range, to ensure that the voltage at the terminals is constant and to remain connected to the mains during the defined voltage step changes. Other rules apply to reactive power and voltage control. Wind turbines should be able to contribute to the system's dynamic capability and reactive energy balance. Reasonable power codes related to reactive power capability range is 0.925 (forward) and 085 (reverse). The GCs require each wind turbine to maintain a constant voltage at the terminal voltage through the automatic voltage regulator.

\subsection{Fault ride- through requirements}

The main concern of the transmission system operators is that they will be able to keep the generators operating in a stable state and connected to the mains when a failure occurs in the transmission system. This is called fault ride through (FRT) or low-voltage-through capability. In general, where the synchronous generators are directly connected to the network, it is expected that they will be disabled when there is a permanent fault in the mains. Other generators connected close to healthy points relatively distant from the point of failure should remain connected to the network and remain stable after the defective part is disconnected from the network. Each network is designed and operated to withstand the sudden loss of a specified rate of production capacity.

In many cases, wind power plants are connected between the rotor shaft of the generator and the rotor by means of a gearbox which increases the rotational speed on the generator side, as shown in Figure 1. While the stator windings are directly connected to the mains, the rotor windings are connected to the mains with two voltage source converters connected to each other, $\mathrm{k}$, this configuration separates the electric frequency of the rotor from the mains frequency and as a result the rotor normally has a speed of $\pm 30 \%$ of the synchronous speed. High wind turbines can operate at optimum rotational speed, where the wind rotor's aerodynamic efficiency is maximum shown as Fig. 3 [41]. 


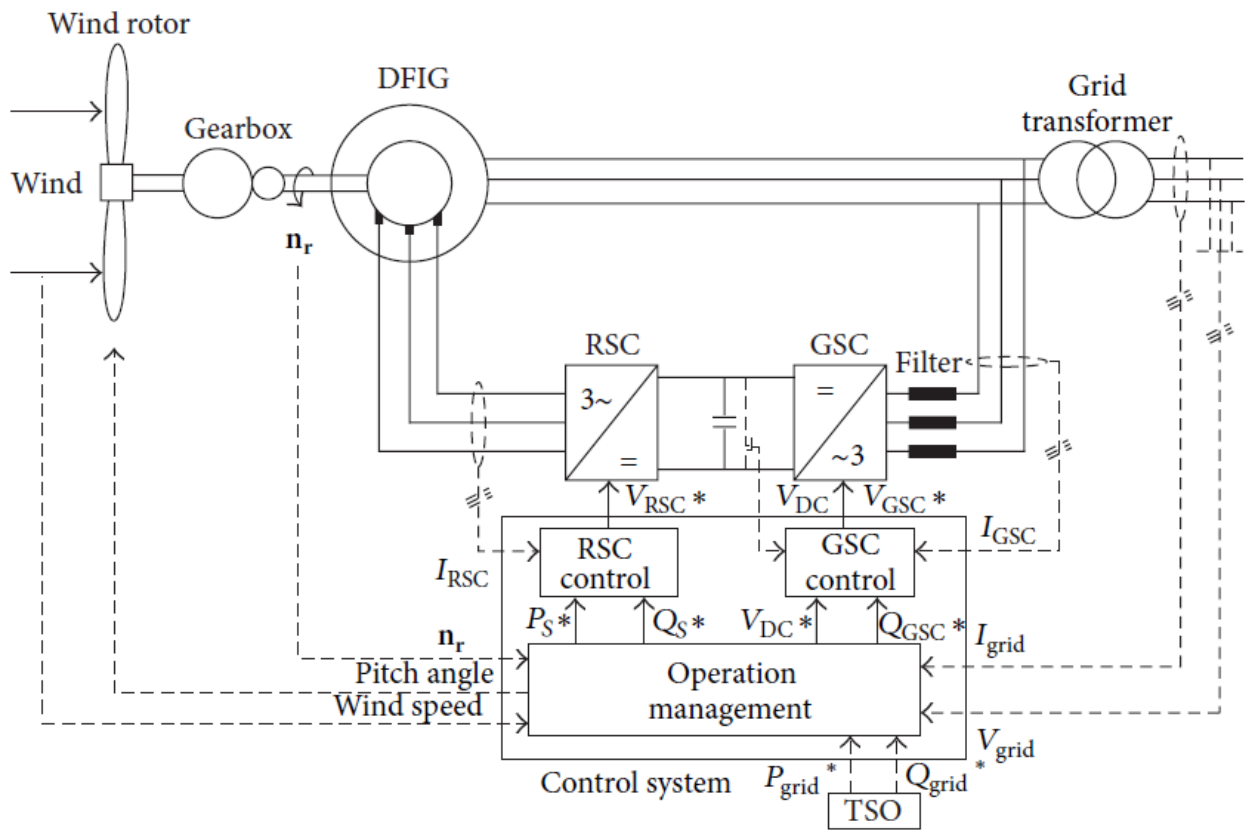

Figure 3. Double feed induction generators-based wind turbine system model.

In this study, the effects of wind turbine system on voltage quality were investigated and the changes in the imbalance in the energy market were evaluated. By highlighting the direct impact of developing wind capacity in energy imbalance, the importance of forecasting in the power market has been demonstrated. Wind turbine installed capacity of renewable origin Turkey's development over the years the share of total installed power shown as Figure 4.

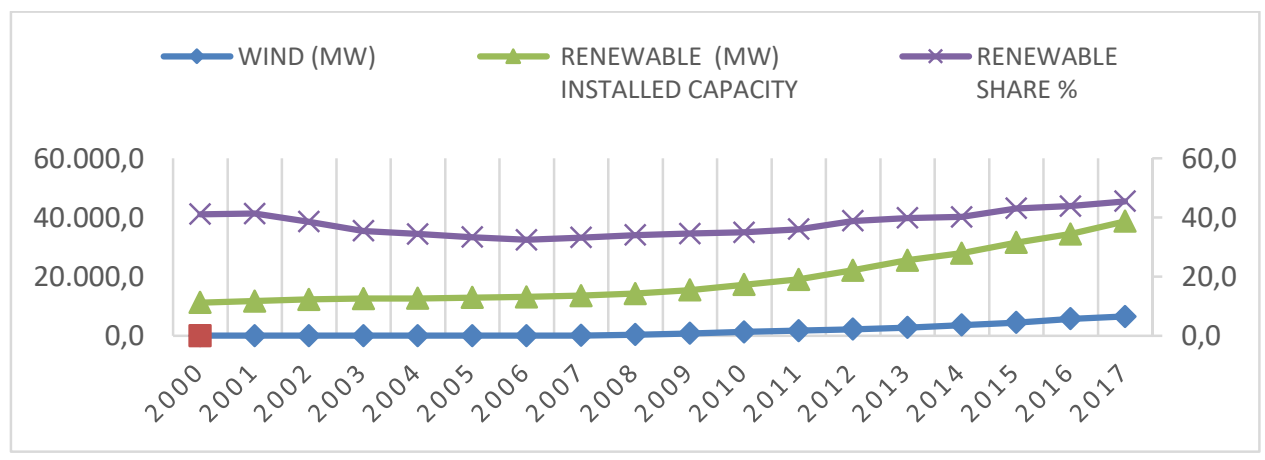

Figure 4. Turkey's development over the years the share of total installed power for WP

\section{Results of Calculations for System Model}

Market players trading in DAM and Day Time Market (DTM) try to eliminate energy imbalances because they do not want to be exposed to prices in the real-time market (balancing power market). There are two reasons for this: the first is the avoidance of the high risk of real-time market prices, and the second is the number of fines paid in addition to this risk. In the current practice, the market players who fall into imbalance are subject to both the higher of the PTF and the higher of the SMP in the buying direction / the lower of the sales direction, as well as a 3\% penalty for these prices. As it is known, while the trade in DAM is reconciled at marginal price, the principle of payment as much as the proposal is applied in DTM. Therefore, both the resources are effectively distributed, and the plants can offer more comfortable prices without trying to estimate the market price. In DTM, bids are given at the estimated market price, not marginal cost.

The change in the amount of energy imbalance increases significantly due to the PV production rate. Figure 5 shows the relationship between positive and negative imbalance value and PV production for our national power system for 2017. The big change in the positive imbalance, which is the result of overproduction on the producer side. In addition, the big change in the positive imbalance, which is the 
result of low consumption on the consumer side. Likewise, the big change in negative imbalance, which is caused by less production on the producer side. In addition, the big change in negative imbalance, which is the result of excessive consumption on the consumer side.

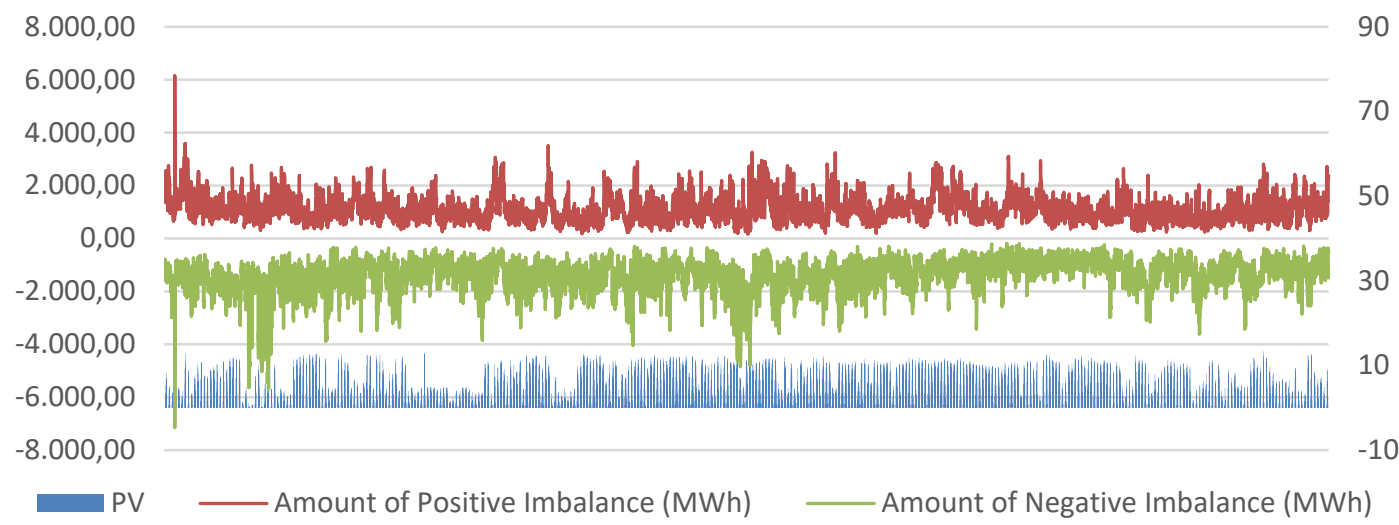

Figure 5. Variation of the imbalance amount for 2017 with PV production

As the share of PV production within the installed power increases, the imbalance value increases. As the share of PV production within the installed power increases, the imbalance value increases. PV capacity increased from 3,420,7 MWh in 2017 to 5,419 MWh in 2018. As a result of this increase, the imbalance increased both positively and negatively. Figure 6 shows the relationship between positive and negative imbalance value and PV production for our national power system for 2018.

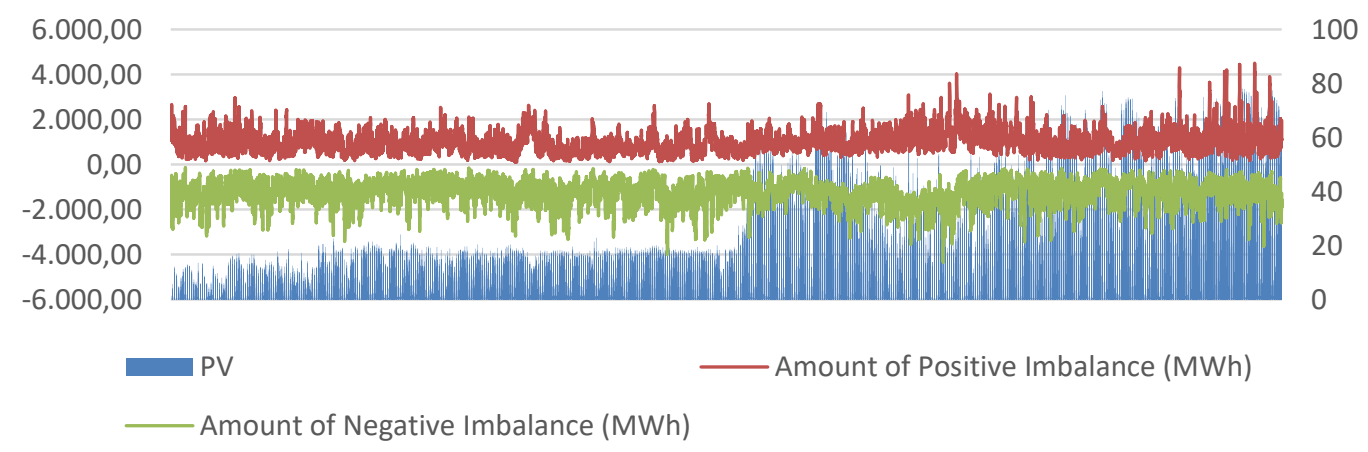

Figure 6. Variation of the imbalance amount for 2018 with PV production

PV capacity increased from 5,419 MWh in 2018 to 6,089 MWh in May 2019. As a result of this increase, the imbalance increased both positively and negatively. Figure 7 shows the relationship between positive and negative imbalance value and PV production for our national power system for May 2019.

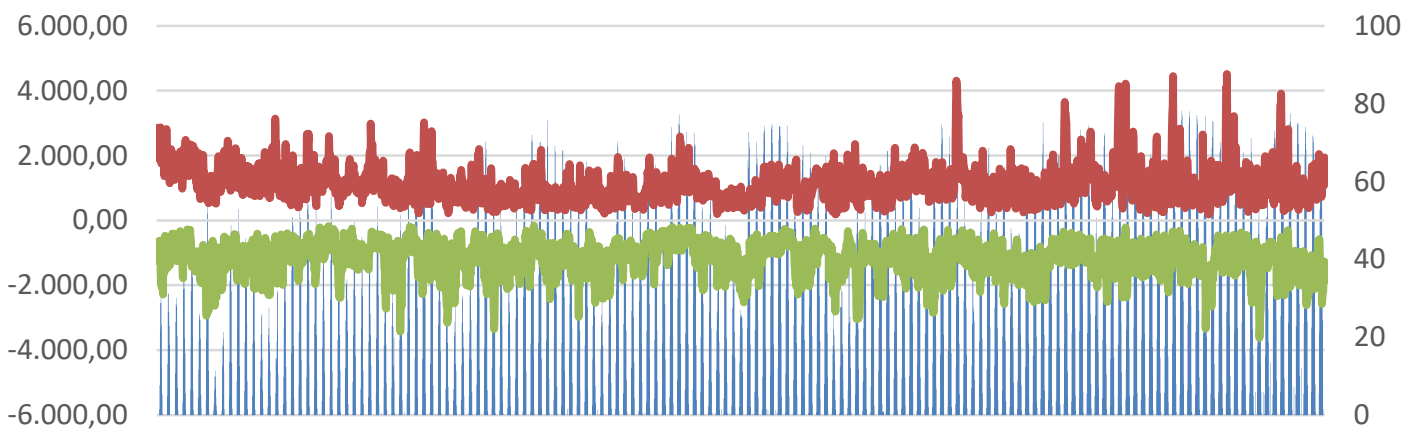

PV $\longrightarrow$ Amount of Negative Imbalance (MWh) Amount of Positive Imbalance (MWh)

Figure 7. Variation of the imbalance amount for May 2019 with PV production 
This imbalance rate is eliminated by the prediction of accurate estimates on the side of the production rather than the correct planning of increasing PV production and based on this, the right production planning in other production plants. Figure 8 shows the comparison of the average values in three separate years. In the comparison, it is observed that the imbalance values increase as the PV ratio increases within the installed power.

Figure 8. Comparison of average values for Solar

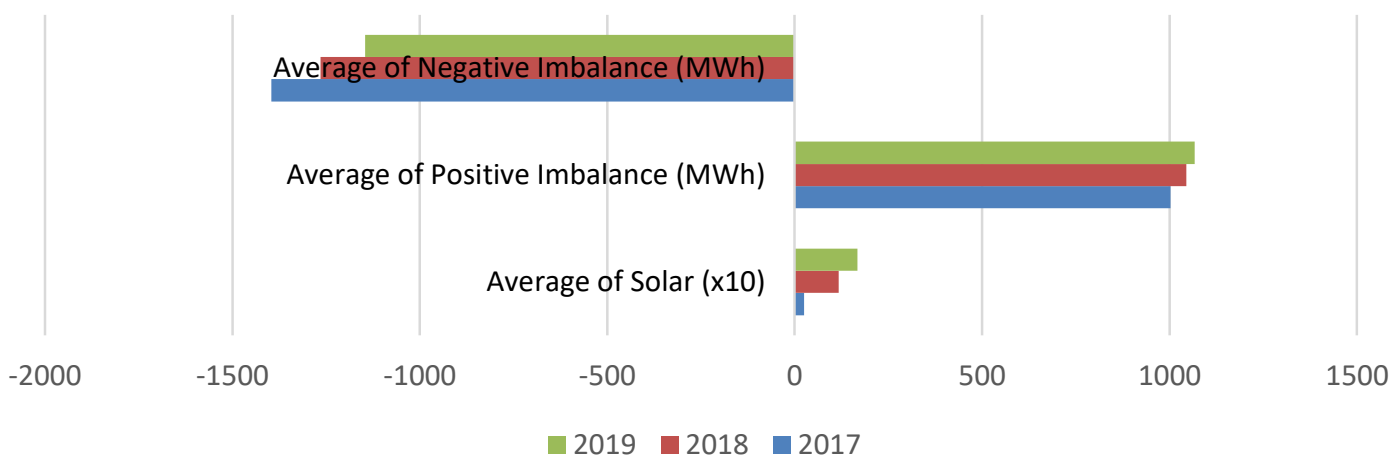

The PQ of wind turbines is defined by their electrical characteristics. The international standards for determining the PQ of wind turbines (IEC 61400-21 and MEASNET) and the national standards of different countries set the requirements for PQ measurements. In the case of switching operations, power peaks, harmonic spring, reactive power, clipping, and electrical behavior are measured according to these standards.

The change in the amount of energy imbalance increases significantly due to the wind production rate. Figure 9 shows the relationship between positive and negative imbalance value and wind production for our national power system for 2017. The big change in the positive imbalance, which is the result of overproduction on the producer side. In addition, the big change in the positive imbalance, which is the result of low consumption on the consumer side. Likewise, the big change in negative imbalance, which is caused by less production on the producer side. In addition, the big change in negative imbalance, which is the result of excessive consumption on the consumer side.

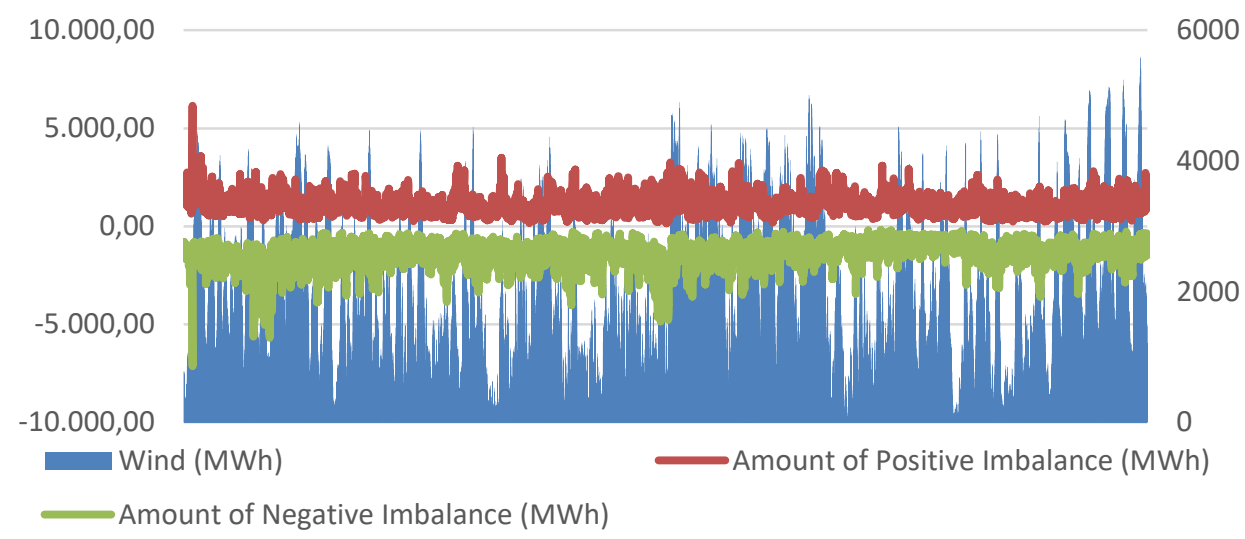

Figure 9. Variation of the imbalance amount for 2017 with wind production

As the share of wind production within the installed power increases, the imbalance value increases. As the share of wind production within the installed power increases, the imbalance value increases. Wind capacity increased from 6,516 MWh in 2017 to 6,723 MWh in 2018. As a result of this increase, the imbalance increased both positively and negatively. Figure 10 shows the relationship between positive and negative imbalance value and wind production for our national power system for 2018. 


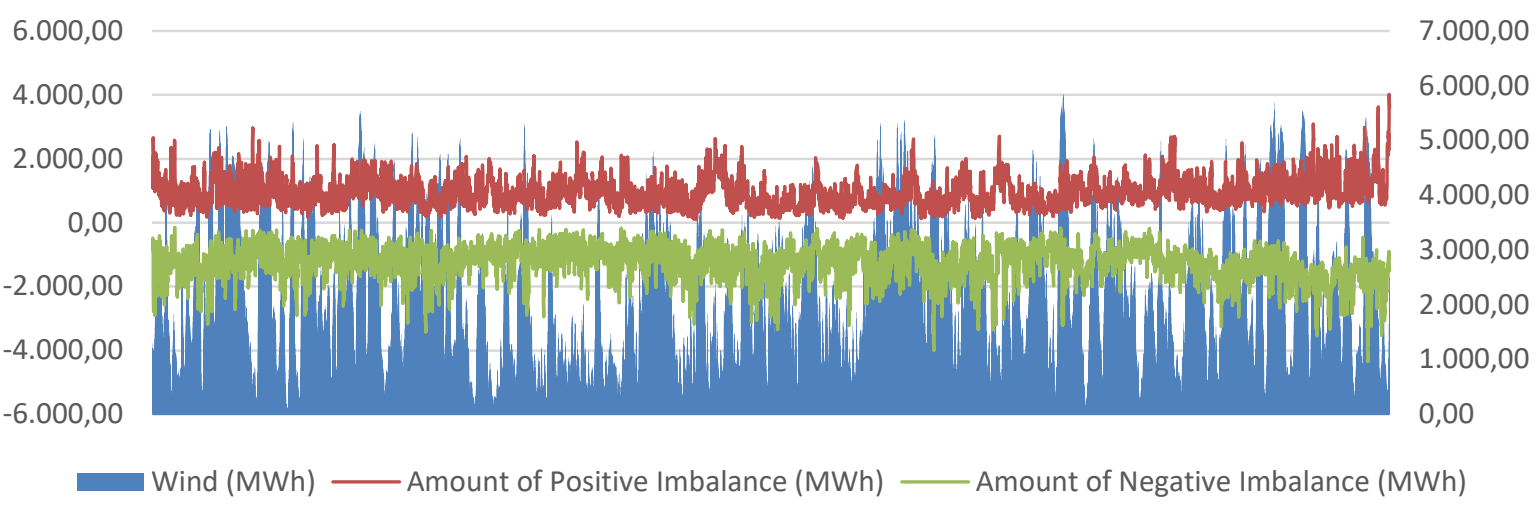

Figure 10. Variation of the imbalance amount for 2018 with wind production

PV capacity increased from 6,723 MWh in 2018 to 7,031 MWh in May 2019. As a result of this increase, the imbalance increased both positively and negatively. Figure 11 shows the relationship between positive and negative imbalance value and wind production for our national power system for May 2019.

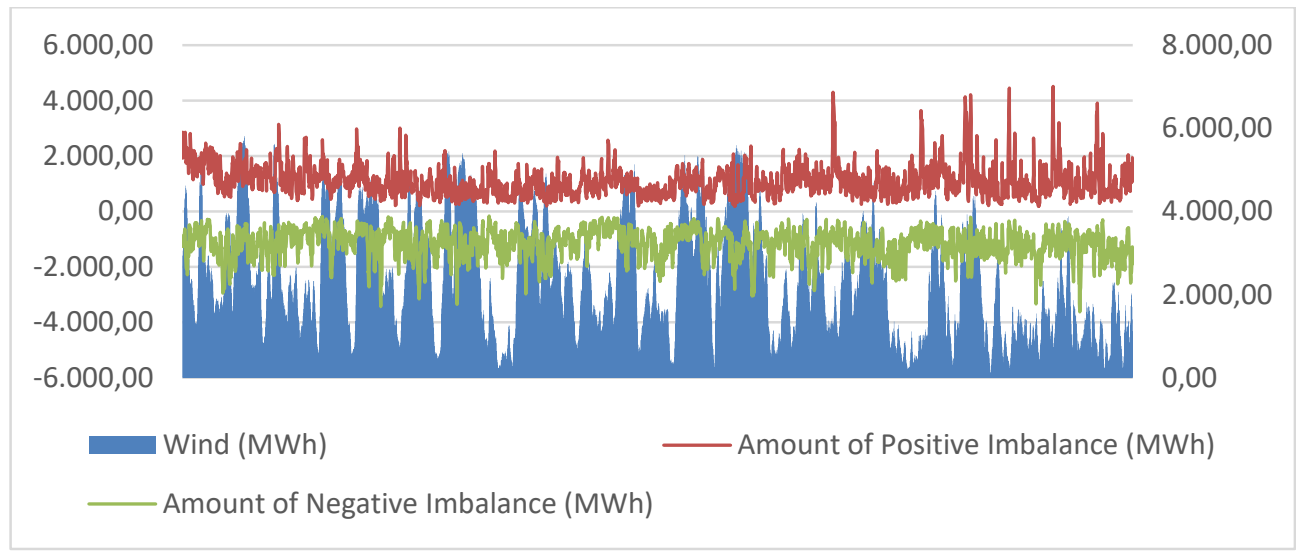

Figure 11. Variation of the imbalance amount for May 2019 with wind production

This imbalance rate is eliminated by the prediction of accurate estimates on the side of the production rather than the correct planning of increasing wind production and based on this, the right production planning in other production plants. Figure 12 shows the comparison of the average values in three separate years. In the comparison, it is observed that the imbalance values increase as the WP increases within the installed power.

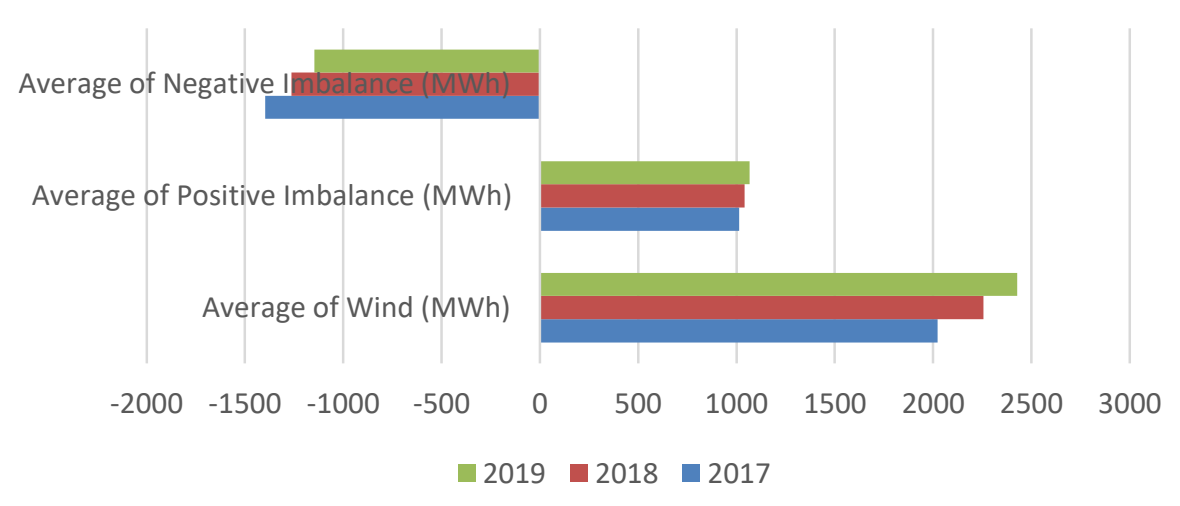

Figure 12. Comparison of average values for wind 


\section{Conclusion}

Positive and negative imbalance is not desirable in power systems. Direct energy quality and energy brings serious economic losses. In order to prevent or minimize this undesirable situation, PV integration has required serious planning. While PV production capacity was $40 \mathrm{MWh}$ in 2014 , the energy deficit was monitored at a very low level. Increased PV capacity from 2015 to 2019 provides 248.8 MWh, 832 MWh, 3,420 MWh, 5,419 and 6,089 MWh, respectively. Developing PV will be ensured by correct forecasting on the costumer side rather than correct planning of production and based on this, correct production planning in other production plants. As a result, this study observed increases in energy imbalance in proportion to the increasing share of PV capacity in installed power.

This scope of work; In recent years, developments in wind turbines have been examined and especially the criteria for compatibility with the grid have been pointed out. Also, the regulations in Turkey were investigated responses to these criteria. The effects of positive and negative imbalance on WP production were investigated and some of these criteria were modeled. In particular, the period in which imbalance occurs and the fact that wind turbines provide reactive power support constitute an important result. In case of network failures (voltage drops) and control of active and reactive power, additional considerations relating to the connection of wind turbines and wind farms, such as the support of the network, to the mains connection are available in the country network code documents. Positive and negative imbalance is not desirable in power systems. Direct energy quality and energy brings serious economic losses. In order to prevent or minimize this undesirable situation, Wind integration has required serious planning. While Wind production capacity was 3,629 MWh in 2014, the energy deficit was monitored at a very low level. Increased PV capacity from 2015 to 2019 provides 4,503 MWh, 5,751 MWh, 6,516 MWh, 6,723 and 7,031 MWh respectively. Developing wind will be ensured by correct forecasting on the costumer side rather than correct planning of production and based on this, correct production planning in other production plants. As a result, this study observed increases in energy imbalance in proportion to the increasing share of wind capacity in installed power. To eliminate this issue, it is needed to make the most accurate production and consumption estimation and optimal planning of spinning reserve capacity $[42,43]$. In future studies, it is planned to develop real power system designs by developing models for integration problem. Thus, the impact status of the system for RES, which is included in the real model, will be examined and PQ will be provided by taking necessary measures.

\section{References}

[1] Borbely, M. and Kreidel J. F., Distributed Generation: The Power Paradigm for the NewMillennium, CRCPress,NewYork, NY, USA, 2001

[2] Barker, P. P. and Mello de R. W., "Determining the impact of distributed generation on power systems. I. Radial distribution systems," in Proceedings of the IEEE Power Engineering Society Summer Meeting, vol. 3, pp. 1645-1656, Seattle, Wash, USA, 2000.

[3] Xin, X. and Hui, L., "Research on multiple boost converter based on MW-level wind energy conversion system", Proceedings of the Eighth International Conference on Electrical Machines and Systems, Nanjing, China, 1046-1049, 27-29 Sept. 2005.

[4] ENTSO-E, ENTSO-E Network Code for Requirements for Grid Connection Applicable to all Generators, 2016

[5] Dugan,, R. C., McGranahan M. F., Santoso S., and Beaty H. W., "Electrical Power System Quality," 2nd ed. McGraw-Hill, 2004.

[6] Eklas H., Mehmet Rida T., Sanjeevikumar P., Selim A., Imtiaj K. Analysis and Mitigation of Power Quality Issues in Distributed Generation Systems Using Custom Power Devices, IEEE Access, Volume: 6, (2018)

[7] Bollen,, M. H. J., "What is power quality?” Electric Power Systems Research, vol. 66, no. 1, pp. $5-14,2003$ 
[8] M.R. Tür, "Solution Methods and Recommendations for Power Quality Analysis in Power Systems", Journal of Engineering and Technology 2;2 1-9, (2018)

[9] James, R. and Petr M. "Towards prediction of photovoltaic power quality," 26th Annual IEEE Canadian Conference, 5-8 May 2013.

[10] Twidell, J., and Weir T. "Renewable energy resources", Routledge, 2015.

[11] Asadinejad A., Varzaneh M.G., Mohajeryami S., and Abedi M., "Using Biomass in Power Generation for Supplying Electrical and Thermal Energy in Iran and Evaluation of Environmental Pollution Spread", Journal of Energy and Power Engineering , Jan. 2016.

[12] Muntwyler, U. "Towards 100\% renewable energy supplies...," in 2015 Tenth International Conference on Ecological Vehicles and Renewable Energies (EVER), pp.1-8, March 31 2015April 22015

[13] Rahimi, K. and Chowdhury B., "A hybrid approach to improve the resiliency of the power distribution system," North American Power Symposium (NAPS), Pullman, WA, 2014, pp. 1-6.

[14] Morsali, R., Ghadimi N., Karimi, M. and Mohajeryami, S. "Solving a Novel Multiobjective Placement Problem of Recloser and Distributed Generation Sources in Simultaneous Mode by Improved Harmony Search Algorithm", complexity journal, 21(1), pp. 328-39, Sep. 2015

[15] Pollin, R., Heintz J., and Garrett-Peltier H., "The economic benefits of investing in clean energy", Center for American Progress and Political Economy Research Institute, 2009.

[16] Demirok, E. P. González, C. Frederiksen, K. H. B. Sera D., Rodriguez P. and Teodorescu R., "Local Reactive Power Control Methods for Overvoltage Prevention of Distributed Solar Inverters in Low-Voltage Grids," in IEEE Journal of Photovoltaics, vol. 1, no. 2, pp. 174-182, Oct. 2011.

[17] Davoudi, M., Cecchi V. and Agüero J. R., "Effects of stiffness factor on bus voltage variations in the presence of intermittent distributed generation," North American Power Symposium (NAPS), 2015, Charlotte, NC, 2015, pp. 1-6.

[18] Parchure, A., Tyler S., Rahimi K., Broadwater R., Dilek M., and Peskin M., "Investigating PV Generation Induced Voltage Volatility for Customers Sharing a Distribution Service Transformer," IEEE conference on Rural Electric Power Conference (REPC), Westminster, CO, 2016.

[19] Taherbaneh, M., Rezaie A. H., Ghafoorifard H., Rahimi K., and Menhaj M. B., "Maximizing Output Power of a Solar Panel via Combination of Sun Tracking and Maximum Power Point Tracking by Fuzzy Controllers", International Journal of Photoenergy, vol. 2010, Article ID 312580, 13 pages, 2010

[20] M. R. Tur and R. Bayindir, "Project Surveys for Determining and Defining Key Performance Indicators in the Development of Smart", International Journal Of Smart Grid, Vol.3, No.2, June, 2019

[21] Lamichhane, S., Nazaripouya H. and Mehraeen S., "Micro Grid Stability Improvements by Employing Storage," Green Technologies Conference, 2013 IEEE, Denver, CO, 2013, pp. 250258.

[22] M. R. Tur, "Reliability Assessment of Distribution Power System When Considering Energy Storage Configuration Technique" IEEE Access, vol 8(1), 2020

[23] Simões, M.G., Busarello T.D.C., Bubshait A.S., Harirchi F., Pomilio J.A., and Blaabjerg F., "Interactive smart battery storage for a PV and wind hybrid energy management control based on conservative power theory", International Journal of Control, pp.1-21. 2015.

[24] Muttaqi,, K. M. and Sutanto, D. "A Novel Approach for Ramp-Rate Control of Solar PV Using Energy Storage to Mitigate Output Fluctuations Caused by Cloud Passing," in IEEE Transactions on Energy Conversion, vol. 29, no. 2, pp. 507-518, June 2014.

[25] Nazaripouya, H., Wang B., Wang Y., Chu P., Pota H. R., and Gadh R., " Univariate Time Series Prediction of Solar Power Using a Hybrid Wavelet-ARMA-NARX Prediction Method", 2016 IEEE PES T\&D, Dallas, Texas, 2-5 May 2016. 
[26] Rahimi, K., R. Broadwater P. and Bank J., "Performance of PV generation feedback controllers: Power factor versus Volt-VAR control strategies," North American Power Symposium (NAPS), 2015, Charlotte, NC, 2015, pp. 1-6.

[27] Tsili, M. and Papathanassiou S., A review of GC technical requirements for wind farms, IET Renewable Power Generation 3 (2009) 308-332.

[28] Altin, M., Goksu O., Teodorescu R., Rodriguez P., B.- Jensen B. and Helle L., Overview of recent GCs for wind power integration, in: Optimization of Electrical and Electronic Equipment (OPTIM), 2010 12th International Conference on, 2010, pp. 1152-1160. doi:10.1109/OPTIM.2010.

[29] Comech, M. P., Garcia-Gracia M., Martin Arroyo S. and Martinez Guilen M. A., Wind farms and GCs, in: G. Krause (Ed.), From Turbine to Wind Farms - Technical Requirements and Spin-O Products, In-Tech, 2011, pp. 17-41.

[30] Gustavo, M. and Gimenez J., Technical and regulatory exigencies for grid connection of wind generation, in: G. O. Suvire (Ed.), Wind Farm Technical Regulations, Potential Estimation and Siting Assessment, InTech, 2011.

[31] Mohseni, M. and Islam S. M., Review of international GCs for wind power integration: Diversity, technology and a case for global standard, Renewable and Sustainable Energy Reviews 16 (2012) $3876-3890$

[32] Ackermann, T., Ellis A., Fortmann J., Matevosyan J., Muljadi E., Piwko R., Pourbeik P., Quitmann E., Sorensen P., Urdal H., Zavadil B., Code Shift: Grid Specifications and Dynamic Wind Turbine Models, IEEE Power and Energy Magazine 11 (2013) 72-82

[33] Borbelyi M. and Kreidel J. F., Distributed Generation: The Power Paradigm for the NewMillennium, CRCPress, NewYork, NY, USA, 2001

[34] Sourkounis, C. and Tourou P., GC Requirements for Wind Power Integration in Europe, in: Conference Papers in Energy, 2013. doi:10.1155/2013/437674.

[35] D'1az-Gonz'alez F., Hau M., Sumper A., Gomis-Bellmunt O., Participation of wind power plants in system frequency control: Review of GC requirements and control methods, Renewable and Sustainable Energy Reviews 34 (2014) 551-564.

[36] Etxegarai, A., Eguia P., Torres E., Iturregi A. and Valverde V., Review of grid connection requirements for generation assets in weak power grids, Renewable and Sustainable Energy Reviews 41 (2015) 1501-1514.

[37] Sutherland, P. E., Ensuring Stable Operation with GCs: A Look at Canadian Wind Farm Interconnections, IEEE Industry Applications Magazine 22 (2016) 60-67.

[38] Rodriguesi, E. M. G., Os'orio G. J., Godina R., Bizuayehu A. W., Lujano-Rojas J. M. and Catal 'ao J. P. S., GC reinforcements for deeper renewable generation in insular energy systems, Renewable and Sustainable Energy Reviews 53 (2016) 163-177.

[39] Dalyi P. A. and Morrison J., "Understanding the potential benefits of distributed generation on power delivery systems," in Proceedings of the Rural Electric Power Conference, pp. A21A213, Little Rock, Ark, USA, May 2001.

[40] TEIAS, Report the amount of installed power in Turkey has reached, 2018.

[41] Sourkounisi C. and Ni B., "Influence of wind-energy-converter control methods on the output frequency components," IEEE Transactions on Industry Applications, vol. 45, no. 6, pp. 21162122, 2009.

[42] M.R. Tur, et. al. Calculation of optimal value of spinning reserve requirement for unit commitment in power systems by considering lost parameters, Journal of the Faculty of Engineering and Architecture of Gazi University 34:3, 1171-1185, (2019)

[43] Tür, M.R. et al., "Impact of Demand Side Management on Spinning Reserve Requirements Designation" International Journal of Renewable Energy Research, Vol.7, No.2, 2017 